\title{
Discurso cientificista nas políticas de currículo no Chile (2003 -2013): o foco no Programa ECBI - Enseñanza de las Ciências basada en la Indagación
}

\section{The discourse of scientism in the Chilean curriculum policy (2003-2013): focus on the ECBI Program - Enseñanza de las Ciências Basada en la Indagación}

Soledad Andrea Castillo Trittini ${ }^{1}$ • Alice Casimiro Lopes ${ }^{1}$

\begin{abstract}
Resumo: Neste artigo apresentamos o que nomeamos como discurso cientificista nas políticas de currículo do Chile no período de 2003 a 2013. Nosso foco de investigação é o programa ECBI - Enseñanza de las Ciências Basada en la Indagación -, desenvolvido por pesquisadores da Faculdade de Medicina da Universidade do Chile e da Academia de Ciências e pelo Ministério da Educação. Defendemos que o discurso cientificista é produzido pela articulação entre diferentes demandas em torno da qualidade do ensino de ciências e da educação, engendrando ações na tentativa de conectar diretamente os especialistas disciplinares, como formuladores de uma pedagogia, ao currículo nas escolas e à formação de professores. Dessa forma, há uma contraposição a uma pedagogia considerada como incapaz de incluir a ciência, em nome de uma pedagogia que se supõe mais efetiva, porque baseada na ciência e na indagação.
\end{abstract}

Palavras chave: Currículo. Discurso. ECBI. Qualidade de ensino. Cientificismo.

\begin{abstract}
In this paper, we present what we name as the discourse of scientism in Chilean curriculum policy from 2003 to 2013. Our research focus is on the ECBI program - Enseñanza de las Ciências Basada en la Indagación - developed by researchers of the Medical Faculty of University of Chile, the Academy of Sciences and the Ministry of Education. We argue that the discourse of scientism is produced by the interaction of different demands on the quality of science teaching and education, which generates actions in an attempt to connect disciplinary experts, as makers of a pedagogy, the curriculum in schools and teacher training. We find, there is a contrast between a pedagogy regarded as unable to include science, with a pedagogy supposed to be more effective, because it is based on science and inquiry.
\end{abstract}

Keywords: Curriculum policy. Discourse. ECBI. Quality of education. Scientism.

\footnotetext{
${ }^{1}$ Universidade do Estado do Rio de Janeiro (UERJ), Programa de Pós-Graduação em Educação, Rio de Janeiro, RJ, Brasil. E-mail: <solecastillo7@hotmail.com>
} 
O Chile vem sendo citado em muitas das discussões atuais sobre políticas de currículo divulgadas no Brasil, como um dos exemplos - talvez o mais exacerbado na América Latina -de políticas neoliberais de privatização da oferta educativa e de ampliação das desigualdades educacionais (BUDNIK et al., 2011; DONOSO DÍAZ, 2011) ou ainda como capaz de associar avanços pedagógicos a processos de diminuição da equidade (ZIBAS, 2002). Ainda assim, ou talvez exatamente por essas características privatistas, é divulgado como possível modelo para reformas curriculares brasileiras ${ }^{2}$ ou como o país latino-americano que mais realizou ações dirigidas à melhoria do acesso e da qualidade da educação (OECD, 2013 apud SCHWARTZMAN, 2007).

Visando a aprofundar essa problematização das políticas, tanto no Chile quanto na capilarização desses discursos no Brasil, apresentamos neste artigo conclusões de uma pesquisa sobre as políticas de currículo para a educação em ciências chilena, com foco no projeto Enseñanza de las Ciências basada en la Indagación (ECBI), dirigido ao segundo ciclo (quinto ao oitavo ano) do ensino fundamental, correspondente a alunos entre dez e 12 anos de idade. Buscamos estar sintonizadas, em um sentido amplo, com estudos sobre políticas curriculares que apostam na complexidade das apropriações de orientações globais na América Latina (BEECH, 2009), com discussões teórico-metodológicas vinculadas a uma ontologia pós-estrutural (OLIVEIRA; OLIVEIRA; MESQUITA, 2013) e que buscam compreender as políticas chilenas como práticas discursivas que projetam subjetivações (INFANTE JARAS; MATUS CÁNOVAS; VIZCARRA REBOLLEDO, 2011). Destacamos a educação em ciências, não apenas por ser a área de atuação profissional de uma de nós, mas também por considerarmos que nessa área, de forma mais contundente, vem sendo construído um discurso que conecta o ensino de certos conteúdos, competências e habilidades ao projeto de produzir identificações de qualidade da educação. Defendemos ser por meio do que denominamos discurso cientificista que vêm sendo produzidas no Chile ações na tentativa de conectar diretamente os especialistas disciplinares, como formuladores de uma pedagogia, ao currículo nas escolas e à formação de professores.

Operamos com o currículo como um espaço de produção cultural e de significação (MACEDO, 2006; LOPES, 2012; LOPES; MACEDO, 2011). Buscamos compreender processos de significação desse cientificismo nos discursos curriculares, entendendo discurso como uma tentativa de estabilizar e frear os diferentes sentidos, sempre decorrente de uma prática em que diferentes demandas são articuladas como resposta à representação de uma ameaça às identidades projetadas (LACLAU, 2000, 2013). A produção discursiva da política de currículo, como já desenvolvido em outros textos (LOPES; CUNHA; COSTA, 2013; MATHEUS; LOPES, 2014), envolve processos de negociação em dadas relações de poder, não sendo decorrente de qualquer centro de poder estável, determinado ou determinável.

\footnotetext{
${ }^{2}$ Ver, por exemplo, a abordagem realizada na entrevista com o sociólogo Cristián Cox, coordenador da Unidade de Currículo e Avaliação do Ministério da Educação do Chile, na Revista Nova Escola. Disponível em: $<$ http://revistaescola.abril.com.br/politicas-publicas/planejamento-e-financiamento/educacao-chile-nossodesafio-426076.shtml>. Acesso em: 27 jan. 2015. Ou os depoimentos apresentados no site da Fundação Lemann - instituição privada que tem atuado de forma sistemática nas políticas de currículo brasileiras - que elogiam as ações no Chile como possíveis exemplos para o Brasil. Disponível em: <http:/ fundacaolemann.org.br/ novidades/a-educacao-no-chile-continuidade-e-coerencia-das-politicas-educacionais >. Acesso em: 27 jan. 2015.
} 
No processo político que constitui o currículo de Ciências, buscamos entender como atuam as comunidades epistêmicas (ANTONIADES, 2003; DIAS, 2013; TORRES; DIAS, 2011). Tais comunidades são subjetivadas em decorrência de ações político-discursivas em defesa de uma qualidade da educação em ciências. A política que produz a significação do currículo, campo sempre em disputa, não é determinada por essas comunidades. Todavia defendemos que elas fazem parte do processo complexo de significação curricular que não se limita aos contextos nacionais.

Tendo em vista esse foco mais amplo na subjetivação da comunidade epistêmica nas políticas de currículo de Ciências, apresentamos neste artigo as conclusões de uma investigação sobre o programa ECBI como uma das ações que nos possibilita compreender as articulações que produzem discursos curriculares para a educação em ciências. O programa ECBI foi introduzido no Chile em 2003, por iniciativa de Jorge Allende e Rosa Devés, e no ano 2005 foi incorporado pelo Ministério da Educação (EVOLUCIÓN..., 2012). Jorge Allende é bioquímico e foi Vicerrector de Investigación y Desarrollo da Universidade do Chile. No ano de 1992, recebeu o prêmio nacional de Ciencias Naturales (UNIVERSIDAD DE CHILE, 2016).

Rosa Devés é bioquímica, faz parte da Academia Chilena de Ciências e é a atual vice-reitora de assuntos académicos da Universidade do Chile. Vale destacar que a Faculdade de Medicina da Universidade do Chile tem tido também um papel central na divulgação dessas atividades voltadas à educação em ciências nos níveis nacional e internacional. Em 2008, esta Universidade foi anfitriã da Conferencia Internacional de Desarrollo Profesional para Profesores de Ciencias de Educación Básica, atividade patrocinada pelo Panel Inter Academias (IAP) $)^{3}$ e pelo Ministério da Educação do Chile, como uma das ações integrantes do Programa ECBI.

Após os resultados da prova Trends in International Mathematics and Science Study (TIMSS) $^{4}$, de 1999 - pela qual, dentre outros aspectos, foi apontado que grande parte dos professores de ciências do ensino fundamental no Chile não sentia confiança em seus conhecimento e habilidades para ensinar essa disciplina aos seus alunos -, se formou uma equipe de trabalho com a tentativa de avançar em relação a essas dificuldades. Essa equipe complementar buscava integrar e aproximar as comunidades científica e escolar, áreas que são consideradas separadas, vinculando a comunidade científica à educação (CHILE, 2009). Ainda em 2003, a Academia Chilena de Ciências se uniu à Faculdade de Medicina da Universidade do Chile, visando a um ensino de ciências de qualidade acessível a todos. A pretensão era de organizar um ensino moderno, capaz de motivar os alunos a ter uma participação mais ativa no processo de aprendizagem das ciências. O ECBI é apresentado então como uma metodologia com objetivos

\footnotetext{
3 “A Rede Global de Academias de Ciências, antigo Painel Inter-Academias (IAP) é uma rede global de 104 academias científicas destinadas a ajudar os seus membros a desenvolverem as ferramentas adequadas para participar das discussões de política científica que ocorrem em importantes foros internacionais". (ACADEMIA BRASILEIRA DE CIÊNCIAS, 2016)

${ }^{4}$ Em 1999, foi aplicada pela primeira vez no Chile a prova TIMSS na oitava série do Ensino Fundamental. TIMSS é um exame internacional sobre as tendências em Matemática e Ciência. "Busca proveer de información de calidad sobre los logros de aprendizaje de los estudiantes de educación básica, y los contextos educacionales en los que aprenden. Se aplica desde 1995, cada cuatro años, a estudiantes de $4^{\circ}$ y $8^{\circ}$ básico en las áreas de Matemática y Ciencias Naturales. Chile ha participado en TIMSS en los años 1999, 2003 y 2011”. (CHILE, 2016)
} 
acadêmico-científicos, sociais e pedagógicos, dentre eles a melhoria da aprendizagem dos alunos em Ciências por meio do desenvolvimento de atividades de investigação e experimentação.

Este programa de ensino é também decorrente de uma iniciativa internacional, com o apoio de cientistas destacados 5 . Em Santiago do Chile, em janeiro de 2002, realizou-se uma reunião na qual participaram a Academia Latino-Americana de Ciências, a National Academy of Sciences (NAS) dos EUA e a Academia de Ciências da França, com a representação de Pierre Léna ${ }^{6}$. Nessa ocasião, segundo ALLENDE (2011), dedicou-se um módulo para demonstrar a metodologia ECBI, atividade considerada fundamental para a reforma curricular no Chile. Dois anos depois, em 2004, a Academia Chilena de Ciências foi escolhida pela IAP para liderar o programa de educação em ciências em nível mundial, sendo definida uma estratégia regional para tais fins. Em junho desse mesmo ano, em Santiago do Chile, se funda a Red Interamericana de Academias de Ciencias (IANAS) e é realizada uma reunião em que se aprova que uma das principais atividades será um "Programa de Educación en Ciencias" governado por um Consejo de Puntos Focales nombrados por las Academias (ALLENDE, 2009, p. 12).

Este conselho se reúne em outubro, na mesma cidade, e realiza o acordo para utilizar o financiamento da IAP para apoiar atividades no hemisfério.

[...] se organiza en Chile en conjunto con el NSRC de Estados Unidos, un taller de planificación estratégica en que participan grupos de Argentina, Brasil, Colombia y Venezuela. • Venezuela inicia un proyecto ECBI (Argentina, Brasil y Colombia ya habían iniciado antes sus programas). $\bullet$ Los Ministros de Ciencia y Tecnología reunidos en Lima en noviembre declaran el Programa de Educación en Ciencias de IANAS como una iniciativa hemisférica (ALLENDE, 2009, p. 12).

A metodologia ECBI foi desenvolvida com financiamento da Fundação Andes ${ }^{7}$ e do Ministério da Educação do Chile. Mais recentemente, conta também com a participação da Faculdade de Ciências da Universidade do Chile em diversas iniciativas, dentre elas a criação do programa "Quiero ser científico", difundido através da emissora de rádio dessa universidade.

\footnotetext{
${ }^{5}$ Por exemplo, temos o caso do físico francês George Charpak, prêmio Nobel de Física do ano de 1992, e de Leon Lederman, físico norte-americano, prêmio Nobel de 1988. Durante a divulgação da metodologia na França, visitaram escolas e interagiram nas salas de aulas com os alunos realizando experimentos.

${ }^{6}$ Doutor em Ciências (1969) e pesquisador em Astrofísica do Observatório de Paris (1971-1983). Foi eleito para a Academia de Ciências em 1991. Atualmente é o presidente da Fundação para a Cooperação Científica O handson. Em uma reunião realizada por motivo da expansão do ECBI, em Santiago, em janeiro de 2002, representou a Academia Latino-Americana de Ciências, a NAS de EUA e a Academia de França. Em Tóquio, no ano 2000, na conferência intitulada Transición hacia la sustentabilidad, na qual se reuniram as academias de ciências de todo o mundo através do Panel Interacademias, na seção outorgada à educação em ciências, Bruce Albert, presidente da NAS, e Pierre Lená (astrofísico francês) apresentaram a metodologia ECBI.

${ }^{7}$ Instituição privada, sem fins de lucrativos, criada em 1983. Tem como propósito colaborar no desenvolvimento do país, “[...] mejorando la calidad de vida y el patrimonio espiritual de sus habitantes.” (FUNDACIÓN..., 2004).
} 
Nesse programa, alunos e professores de escolas de ensino fundamental e médio se reúnem com pesquisadores que comentam suas investigações em andamento e, conforme a temática proposta pelo programa, abordam determinados assuntos.

Por intermédio da investigação do ECBI, tem sido possível acessar materiais de características diferentes e tratá-los como superfícies textuais que mobilizam sentidos referentes à necessidade de aproximar as comunidades científica e escolar e de constituir um modo de conceber a aprendizagem científica. Os materiais por nós investigados são documentos do Ministério da Educação ou resultado de intervenções de representantes da comunidade científica que participam de maneira ativa nas diversas atividades promovidas pelo ECBI. Caracterizam-se assim como documentos legais, trabalhos de professores em congressos (comunicações, pôster e oficinas), sites na internet, entrevistas, livros e artigos citados nos documentos ministeriais. Com a escolha desses materiais para interpretação, operamos com o entendimento de que diferentes instituições e atores sociais, dentre eles professores das escolas, participam da produção de sentidos das políticas.

Na promoção na América Latina ${ }^{8}$, a Red Interamericana de Academias de Ciência (IANAS), em 2007, elaborou um projeto financiado pelo Fondo Especial Multilateral del Consejo Interamericano para el Desarrollo Integral (FEMCIDI), vinculado à Organização de Estados Americanos (OEA), que tornou possível a realização de projetos piloto associados ao ECBI em Bolívia, Peru, República Dominicana, Guatemala e Costa Rica. Em 2008, no Chile9 , foram aprovados cursos ECBI para professores de ensino médio (ALLENDE, 2009).

No Chile, a metodologia ECBI começou como uma iniciativa considerada "independente", organizada por uma equipe mista de cientistas e educadores, inicialmente em seis escolas com uma cobertura de 1000 alunos na Comuna de Cerro Navia, um bairro da periferia da capital Santiago, onde vivem famílias, em sua maioria, de renda baixa e de alta vulnerabilidade social. Nesse mesmo ano, o programa foi ampliado, abarcando mais dois bairros com as mesmas características, incluindo mais 24 escolas e abrangendo também mais anos de escolarização: primeiro e segundo ano do Ensino Fundamental.

Alcançando maior impacto na política educacional em geral, o Ministério da Educação, no ano de 2005, incorporou o ECBI, como uma iniciativa experimental, a outra proposta curricular - Lecto: escritura y Matemática (LEM) -, sendo defendida a complementaridade entre essas ações (EVOLUCIÓN..., 2012).

Tais iniciativas curriculares no Chile não são isoladas. Fazem parte de um movimento mais amplo de mudanças educacionais que começou após o período da pós-ditadura (1990), desenvolvido sob o marco da Reforma Educativa, de 1996, e da Lei Geral de Educação de

\footnotetext{
${ }^{8}$ Têm sido realizadas no Chile duas Oficinas Interamericanas de Planejamento Estratégico. Por meio delas, tem sido apoiado o desenvolvimento de projetos ECBI na Venezuela, Panamá, Bolívia e Peru. O programa ECBI tem colaborado com projetos de educação em ciências na Argentina, Brasil, México, Colômbia, Peru e Bolívia, tendo sido realizado neste último um intercâmbio, apoio e capacitação de profissionais (ALLENDE, 2011). No Brasil, nos anos 2008 e 2009, teriam sido aprovadas a geração e distribuição de novos módulos do ECBI, assim como oficinas regionais e sub-regionais (ALLENDE, 2009).

${ }^{9}$ No Brasil, as atividades estiveram voltadas para a geração e distribuição de novos módulos e workshops regionais e sub-regionais (ALLENDE, 2009).
} 
2009. Somam-se a esses registros legais, constantes ajustes curriculares, quase com a mesma frequência com que foram mudando as autoridades políticas ${ }^{10}$.

Durante esse período, a educação em ciências no Chile tem permanecido em debate, por vezes tendo maior importância e outras sendo considerada como uma disciplina secundária, frente a disciplinas como Linguagem e Matemática, priorizadas por terem posição mais estável no currículo, assim como maior carga horária. No ano de 1996, na primeira reforma curricular do período da pós-ditadura, promulgada pelo Decreto no 40 , a disciplina Ciências foi reestruturada, tornando-se um sector de Ciências, subdividido em três sub-sectores ${ }^{11}$ : Comprensión del Medio Natural, Socialy Cultural, que trata de forma integrada o mundo material e humano (primeiro segmento); Estudio y Comprensión de la Naturaleza (segundo segmento) e Estúdio y Comprensión de la Sociedad (segundo segmento) (CHILE, 1996). Foi também enfatizada a necessidade de fazer mudanças na metodologia de ensino, tencionando tornar a disciplina mais centrada no aluno (CHILE, 1996, p. 112). Ao mesmo tempo, foram outorgadas mais horas à disciplina Ciências: de duas para três. Tais transformações buscaram atingir um novo enfoque multidisciplinar, voltado para a integração entre Física, Química e Biologia, sendo introduzidos novos conteúdos que as representavam de forma mais explícita ${ }^{12}$.

Em 2009, durante o governo de Michelle Bachelet (2006-2010), foi promulgada a Lei Geral de Educação. Nos documentos curriculares de 2009, foi proposto o vínculo entre conhecimentos, capacidades, habilidades e a relação saber-fazer (CHILE, 2009), sendo também incorporado o eixo denominado "Habilidades de pensamiento científico" na disciplina de Ciências no Ensino Fundamental ${ }^{13}$.

No plano de estudos elaborado durante o governo de Sebastian Piñera (CHILE, 2012), foi conferida maior ênfase a temas referentes à investigação cientifica, sendo explicitadas as "Habilidades de Investigación Científica" e as etapas a seguir nesse tipo de atividade. Os eixos temáticos "Ciencias de la vida", "Ciencias físicas y química" e "Ciencias de la Tierra y el Universo" foram introduzidos como forma de organizar os conteúdos e habilidades, com o intuito de que os objetivos associados a eles fossem mais bem mensurados (CHILE, 2012, p. 6).

\footnotetext{
${ }^{10}$ Durante o governo de Patricio Aylwin (1990-1994), foram desenhadas as linhas gerais para a reforma de 1996, promulgada durante o governo de Eduardo Frei Ruiz Tagle (1994-2000). Em 2002, durante o governo de Ricardo Lagos (2000-2006), foi realizado um novo ajuste curricular que incluía as áreas de Língua e Matemática. Em 2009, durante o governo de Michelle Bachelet (2006-2010), foi promulgada a Lei Geral de Educação. Em 2012, durante o governo de Sebastian Piñera (2010-2013), foi elaborado um novo documento com novas bases e planos de estudo.

${ }^{11}$ Nos documentos aparece a palavra sub-sector, em termos de organização curricular tal palavra corresponde à utilização da palavra disciplina. A mudança de disciplina para sub-sector que faz parte de uma mudança maior do currículo em geral obedeceria a razões “[...] técnico-pedagógicas, en agrupaciones o estructuras disciplinarias menores que ordenen los objetivos y contenidos que, de acuerdo con el grado de madurez biológica y psicológica del niño, deben ser alcanzados al finalizar cada nivel en que se divide el proceso de 8 años de estudios." (CHILE, 1996, p. 12).

${ }^{12}$ Antes dessa mudança, os conteúdos de Física, Química e Biologia não eram significativos no segundo segmento do ensino fundamental. Eles eram aprofundados em disciplinas no ensino médio.

${ }^{13}$ No currículo do ano 2009, a organização disciplinar foi novamente reestruturada sendo novamente reorganizadas em disciplinas (sectores de aprendizaje) e já não mais em setores e sub-setores com o objetivo de "[...] adecuar el currículum nacional a las nuevas exigências educacionales." (CHILE, 2009, p. 1).
} 
Compreendemos que marcos legais, como os anteriormente citados, projetam sentidos para as políticas, são produzidos por articulações políticas que tentam estabilizar esses sentidos. Tal estabilização, contudo, nunca é definitiva, fazendo com que o texto legal não encerre a luta política. Seus sentidos são permanentemente reconstruídos em dinâmicas contextuais. São submetidos a traduções, suas leituras são permeadas por conflitos, por disputas pela hegemonização de certos significados. Tal processo faz com que tais textos sejam tentativas de representação da política, pretensões de fechamentos de sentidos que não são efetivamente fechadas e não compõem uma totalidade capaz de ser apreendida de uma vez por todas (LOPES, 2012, 2014). Uma vez que não temos a pretensão de registrar a totalidade da política - por impossibilidade não apenas empírica, mas sobretudo teórica - e tampouco concebemos como possível estabelecer uma origem para esses discursos, como um conjunto de discursos estabilizados em algum ponto, focalizamos o ECBI como uma estratégia política específica. Consideramos que o ECBI tem ganhado cada vez mais espaço e visibilidade, ainda que seja uma dentre tantas outras ações constituintes da política de currículo. Por meio da pesquisa dessa estratégica educativa, buscamos identificar demandas e sentidos para a educação em ciências.

Considerando tal perspectiva, a leitura aqui apresentada também é parcial. Interpretamos, por meio da investigação do ECBI, o discurso cientificista, considerando-o capaz de produzir subjetivações pedagógicas e constituir uma comunidade epistêmica em defesa da atuação de cientistas e suas instituições no currículo de Ciências, como forma de garantir a qualidade da educação.

\section{Discurso cientificista no currículo do Chile}

Diferentes atores e instituições sociais atuam nas políticas de currículo, fazendo consultorias, formulando diagnósticos e propostas para o governo, de forma mais ou menos organizada, atuando diretamente a convite do governo ou em projetos paralelos que, por vezes, se referenciam em orientações ministeriais e outras vezes delas se distanciam ou sequer as consideram diretamente. No que concerne à metodologia ECBI, podemos situar como atores importantes os cientistas já citados, que se envolveram no desenvolvimento do projeto, bem como as instituições universitárias que apoiaram sua realização, notadamente a Universidade do Chile.

Apoiando-nos em Laclau (2000), todavia, não consideramos produtivo considerar tais atores, grupos e instituições que protagonizam a política como centros de poder identitariamente constituídos. Consideramos que se forma uma comunidade epistêmica que atua na política em nome do conhecimento especializado, mas os modos de identificação desta comunidade e de seus conhecimentos não são definidos fora do jogo da política em questão. Subjetivações/ identificações são produzidas em um processo político, contingente e provisório, como efeito da articulação política que significa o currículo de uma dada maneira. Significações identitárias são constituídas, porque demandas são articuladas e equivalências são estabelecidas contra um nome, uma diferença considerada antagônica à própria realização identitária (LACLAU, 2000). Em outros termos, entendemos com Laclau (2000) que a possibilidade de constituição de uma totalidade significativa se dá traçando seus limites por meio da expulsão de uma diferença que antes lhe pertencia, um particular que é expulso da cadeia e passa a funcionar como antagonismo, constituindo dessa forma um exterior contra o qual as diferenças se equivalem. 
Propomo-nos a entender esse discurso que subjetiva diferentes atores, grupos e instituições atuantes na política e, assim, constitui uma comunidade epistêmica que, por sua vez, também reforça esse mesmo discurso que a constitui. Defendemos que tal comunidade, no momento atual, é subjetivada como cientificista por conceber a possibilidade de que os métodos da ciência sejam aplicados no campo educacional, visando a solucionar questões de ensino e aprendizagem e a garantir disposições científicas consideradas importantes no contexto social de forma mais ampla. São construídos processos que tentam direcionar as políticas, visando a promover maior interesse por temas científicos, ao mesmo tempo em que a ciência, ou mais precisamente uma "pedagogia científica", se torna o centro na tomada de decisões educativas.

A construção desse discurso é baseada na pressuposição de uma falta (social) de conhecimentos científicos. Não se trata apenas de um desconhecimento de conteúdos científicos para a realização de avaliações centralizadas ou mesmo para atender finalidades de formação profissional. Trata-se de uma falta de conteúdos considerados capazes de tornar o aluno mais consciente e mais participativo nas questões que se referem à ciência e à sociedade de maneira geral. É afirmado haver um desinteresse dos jovens em realizar estudos associados à ciência e à tecnologia, o que levaria à atual diminuição na formação de cientistas no Chile, assim como a suposta não compreensão, por parte da comunidade geral, em relação aos temas científicos mais correntes.

Busca-se assim constituir um modo científico de ver o mundo, visando à formação do cientista. Igualmente esse modo científico é defendido como capaz de auxiliar o processo de ensino e aprendizagem de forma mais ampla. Há uma tentativa de desconsiderar/contrapor-se/ questionar toda pedagogia (não científica) que não seja significada como capaz de contribuir para sanar essa falta de conhecimento científico.

Dessa maneira, o ECBI é uma metodologia que tenta intervir de maneira profunda na educação em ciências dirigida aos alunos do ensino fundamental e o faz dentro dos parâmetros curriculares estabelecidos pelo currículo chileno. No texto das bases curriculares, quando se defende a importância de os alunos se abrirem à ideia de que a ciência não é imutável, bem como a necessidade de certa expertise que permitiria uma mirada cientifica, busca-se apoio em Harlen (2010 apud CHILE, 2012, p. 2) e se afirma que: “[...] la asignatura promueve una actitud de respeto hacia las pruebas o evidencias, un contacto reflexivo con el mundo natural y una actitud flexible para reconsiderar ideas carentes de sustento empírico".

De acordo com o exposto, ao ter como objetivo fazer uma conexão entre a compreensão que se tem do mundo e a forma como se desenvolve essa compreensão, o entendimento

\footnotetext{
${ }^{14}$ No livro "Principios y grandes ideas de la ciencia en educación" (HARLEN, 2010), a evidência seria uma forma de desenvolver capacidades científicas através da metodologia indagatória. A evidência seria uma espécie de ponte para aproximar o interesse dos alunos pela ciência e a forma como os científicos trabalham o que resultaria em um maior interesse dos alunos pela área científica.

${ }^{15}$ As "grandes ideas de la ciencia" se referem a "ideias chaves" (HARLEN, 2010, p. 2), tópicos de tipo conteudista (movimento, força, energia do universo, etc) e são referenciadas como sendo um pilar para ajudar os alunos a entender "aquello que los rodea y a tomar parte en las decisiones como ciudadanos informados en un mundo donde la ciencia y la tecnologia han aumentando significativamente.” (HARLEN, 2010, p. 7).
} 
em relação à "evidência"14 e às "Grandes Ideas de la Ciencia"15 teria um papel fundamental, pois a ciência, como uma forma de compreender o mundo, "resultaria más estimulante para los estudiantes que cuando se ve como conjunto de procedimientos mecánicos y de respuestas correctas establecidas" (HARLEN, 2010, p. 12). Com isso, tenta-se dar uma abertura em relação à ideia que comumente se tem da ciência. Fazemos menção a esse objetivo como sendo uma "tentativa", pois, ao mesmo tempo em que se projeta essa abertura do campo, a ciência é colocada como uma forma sistemática e mais valorizada de conhecer o mundo. Entendemos que esta dinâmica é parte do processo em que diferentes concepções são articuladas na constituição hegemônica em que diferentes sentidos tendem a ser fixados (LACLAU, 2013).

Nesse processo, há o posicionamento da ciência como uma metodologia possível de guiar o aluno na aquisição "de competências que preparem a los niños para desenvolverse en la sociedad actual" (CHILE, 2012, p. 1). O desenvolvimento de habilidades de investigação científica adquire relevância em relação aos procedimentos elaborados nesse âmbito, como "el planteamiento de problemas, la formulación de hipótesis, la observación sistemática, la realización de experimentos, el registro y el análisis de información y la puesta en común de ideas en forma colectiva" (HARLEN, 2010, p. 2).

O currículo é construído de maneira a valorizar aspectos científicos que os alunos devem adquirir, tal como a aplicação de "[...] habilidades científicas y que asuma las actitudes inherentes al quehacer de las ciencias para obtener evidencia, evaluarla [...]” (CHILE, 2013a, p. 3). Também é valorizada a apropriação do

[...] valor formativo intrínseco de las formas de pensamiento típicas de la búsqueda científica e a necessidade de adquirir conceptos y principios fundamentales acumulados por las ciencias, los modos de proceder de la ciencia, con el fin de que alumnos y alumnas desarrollen las habilidades de pensamiento propias del quehacer de la ciência. (CHILE, 2009, p. 243)

O ECBI é uma proposta que expressa essa tentativa de aproximação entre as ciências e a escola. Ao ter como um dos seus objetivos "contribuir al cambio y la innovación desde la construcción de cercanía, complementación, alianzas y redes entre la comunidad científica y el mundo docente y escolar" (ECBI CHILE, 2015), o programa é organizado de maneira a encurtar a distância entre os cientistas e a escola. Do ponto de vista pedagógico, há uma tentativa de realizar um processo de transição que vai desde a "metodología tradicional hacia la metodología indagatória” (DEVÉS; REYES, 2007, p. 5). Igualmente, procura-se "reemplazar la relación tradicional entre ciencia y educación que superpone saberes, pero no los integra, por una relación basada en el trabajo y la creación conjunta, capaz de producir un cambio verdadero en el sistema" (DEVÉS; REYES, 2007, p. 2). O ensino de Ciências é interpretado como um ensino integral, entendido sob a base de a ciência ser um "conocimiento sobre el mundo, significativo se conectado com la experiência y contextos vitales de los alumnos y alumnas." (CHILE, 2009, p. 1). Ao justificar a disciplina Ciencias Naturales, se aponta que ela "otorga al estudiante la posibilidad de aplicar una mirada científica a su aproximación a la naturaleza." (CHILE, 2012, p. 1). Pretende-se igualmente desenvolver um olhar crítico e de proteção ao meio ao qual pertence, mas esse sentimento de proteção só pode ser adquirido se os alunos adquirirem essa base científica. 
Toda pedagogia que não considera suficientemente a ciência na sua forma de ensino tende a ser excluída desse debate, sendo a ciência posicionada como um bom "método para descubrir y aprender y una excelente escuela para adquirir competencias que preparen a los niños y jóvenes para desenvolverse en una sociedad que cambia constantemente y que posee una sobre abundancia de información” (DEVÉS; REYES, 2007, p. 2). Nesse sentido, tem-se a pretensão de combater a educação científica de má qualidade. A "ciencia bien enseñada seria aquela que considera as alianzas entre o mundo académico e a comunidad escolar" (DEVÉS; REYES, 2007, p. 2) e a que permite os alunos se apropriarem "[...] de las formas de pensamiento que subyacen a la búsqueda científica” (DEVÉS; REYES, 2007, p. 2).

"A pedagogia basada en la indagación" (DEVÉS; REYES, 2007, p. 3) é contraposta às pedagogias não-científicas, interpretadas como "basada en la transmisión de contenido". Com a pedagogia baseada na indagação, se estaria investindo em um "conocimiento nuevo sobre el proceso de aprendizaje que emerge de la investigación” (DEVÉS; REYES, 2007, p. 3) ao implicar "procesos similares a los que usan los científicos en la búsqueda de conocimiento" (DEVÉS; REYES, 2007, p. 3). Os professores seriam, assim, uma espécie de "guia" nesse processo que se concretiza em uma aula de ciências que se configura em torno a:

[...] un problema, comparten sus ideas, se hacen preguntas y predicen resultados (focalización); realizan observaciones, experimentan y registran sus resultados (exploración); analizan la relación entre sus predicciones y los resultados observados (reflexión), y utilizan el aprendizaje recientemente adquirido para resolver un problema nuevo (aplicación). (DEVÉS; REYES, 2007, p. 3)

A falta de conhecimento científico dos professores é outro desafio considerado como possível de ser superado através do ECBI, influindo "nos programas de formación inicial de profesores en las universidades e contribuindo a modernizar la enseñanza de la didáctica de las ciências" (DEVÉS; REYES, 2007, p. 117). Isso seria possível ao incrementar "la interacción entre las Facultades de Educación y de Ciencias en cada universidad y vinculando al sistema educacional en general con la comunidad científica nacional e internacional" (DEVÉS; REYES, 2007, p. 117). A defesa da atuação dos cientistas e do mundo acadêmico no espaço escolar é parte da relação entre contextos que vão muito além desse contexto em particular e faz parte do processo de subjetivação pedagógica que constitui a comunidade epistêmica em foco.

Para tal propósito, a aquisição de novas competências, consideradas atualmente como não incorporadas pelos professores, e a construção de novas estratégias são chaves para dar andamento a esta metodologia que considera “[...] que todos los profesores tienen la capacidad para adquirir estas nuevas competencias, assim como todos los niños pueden aprender, pero que esto requiere de estrategias específicas y una inversión substancial” (DEVÉS; REYES, 2007, p. 10). Uma pretensão de renovar amplamente os objetivos é vinculada a esta metodologia que tem como um dos seus propósitos mais significativos “[...] mejorar a la sociedad a través del 
mejoramiento de los sistemas educacionales y el aprendizaje de todos los ciudadanos" (FULLAN, $2005^{16}$ apud DEVÉS; REYES, 2007, p. 10). Estes propósitos procuram um alinhamento em relação ao currículo nacional, propiciando instâncias de criação de unidades didáticas em conjunto entre professores, cientistas e um especialista em metodologia indagatória.

As ações empreendidas pelo ECBI são propostas com base na teoria de aprendizagem construtivista. As referências ao construtivismo podem ser lidas em trechos como:

El constructivismo promueve unos de los objetivos más importantes de la enseñanza de las ciencias, la comprensión profunda del conocimiento. El modelo de aprendizaje basado en el constructivismo permite que cada alumno construya una comprensión de fenómenos de la realidad. (EVOLUCIÓN..., 2012)

Simultaneamente à construção de procedimentos pelo próprio aluno para compreender e resolver situações-problema, há o objetivo de construção de capacidades. Pretende-se propiciar um conjunto de mudanças e assim fortalecer "la autonomía y el liderazgo de los distintos actores (profesores, monitores) de manera que puedan aportar creativamente a sus comunidades de aprendizaje" (DEVÉS; REYES, 2007, p. 11). Trata-se de uma pedagogia efetiva para a ciência (HARLEN, 2010), incluindo aspectos como "la indagación, constructivismo individual y social y el uso de la evaluación formativa” (HARLEN, 2013, p. 51).

O construtivismo nesse sentido se refere à:

[...] revelación consciente de las ideas, habilidades y actitudes previas de los estudiantes en relación a un evento o fenómeno a ser estudiado y a hacer uso de esta información para ayudar a desarrollar el aprendizaje. Esto reconoce que los estudiantes son agentes en el desarrollo o cambio de sus ideas y en la práctica significa también la necesidad de ayudarlos a considerar ideas alternativas que pueden ser más útiles que las suyas para explicar el mundo a su alrededor. Una importante fuente de ideas alternativas es la discusión de las ideas de otros; en lugar a que los estudiantes desarrollen sus ideas individualmente (constructivismo individual) es más fructífero motivar la discusión y argumentación a través de la cual las ideas se desarrollan socialmente. El proceso de comunicar y defender las ideas, ayuda a los estudiantes a reformular sus propias ideas tomando en cuenta las ideas de los demás. (HARLEN, 2010, 57)

\footnotetext{
${ }^{16}$ Colaborador do programa ECBI, pesquisador educacional canadense e ex-reitor do Instituto de Estudos em Educação de Ontário (Ontario Institute of Studies in Education - OISE). Ele é conhecido por sua experiência em reforma educacional, bem como por estudos nos distritos escolares, grupos de professores, institutos de pesquisa e governos.
} 
O construtivismo está assim associado à ideia de comunidade com que é desenvolvida a metodologia ECBI. Faz-se referência, por exemplo, ao enfoque sistêmico que incorpora, entre outras, a participação da comunidade, assim como a "instalación de una cultura de desarrollo profesional que asegure la formación continua y que contribuya a la generación de una comunidad de aprendizaje" (DEVÉS; REYES, 2007, p. 10). A estratégia desse "enfoque sistêmico", na forma mencionada pelo programa, associa-se, em cinco áreas-chave, à forma como a comunidade como um todo deve ser envolvida no processo: “[...] implementación curricular, desarrollo profesional, materiales educativos, evaluación y participación de la comunidad" (ECBI CHILE, 2015). Estas áreas são mencionadas da seguinte maneira:

1. Currículo científico que define los principales conceptos científicos que se deben aprender en cada nivel. 2 Materiales apropiados para que los niños aprendan activamente esos conceptos. 3 Desarrollo profesional de los profesores que inicie y refuerce permanentemente la preparación de los docentes para usar la metódica ECBI profundizando sus conocimientos científicos. 4. Evaluación formativa de la implementación de la metódica y a mediano y largo plazo evaluación sumativa del impacto de la metódica en el manejo de los conocimientos científicos y la capacidad de resolver problemas de los alumnos. 5. Involucramiento de la comunidad en la educación en ciencias (científicos, padres, autoridades políticas, empresas, etc.) (ALLENDE, 2011, p. 7)

Faz-se menção à participação da comunidade, principalmente tendo em vista a interação entre "autoridades educacionales a nivel comunal, regional y nacional" assim como a "difusión del programa hacia la comunidad (padres, profesores, autoridades comunales, educadores, científicos, políticos) (DEVÉS; REYES; 2007, p. 5) por meio das “Clases Magistrales". Como se esclarece em um dos artigos referente a este programa:

El principal desafío para el programa ECBI en un escenario de crecimiento será mantenerse fiel a sí mismo y conservar sus elementos distintivos, en particular su carácter sistémico. Para ello es fundamental potenciar los liderazgos en todos los niveles y facilitar la interacción entre las personas y las instituciones. (DEVÉS; REYES, 2007, p. 14)

Entendemos que este componente colaborativo tem uma importância particular ao ser um elemento constitutivo na criação e manutenção de uma cultura científica. Por meio dessa ideia, tenta-se incluir a participação dos outros membros da comunidade ao realizar as chamadas "clases magistrales".

Para tal, é também estimulada a realização de feiras científicas e eventos onde os alunos podem apresentar e demonstrar as aprendizagens alcançadas. Nesse tipo de atividades, o foco é a aquisição de aprendizagens desenvolvidas de forma "similar" à maneira como os acadêmicos trabalham nas suas disciplinas de referência. Associado ao objetivo de qualidade para a educação, se aponta a necessidade de: “[...] involucrar a distintos miembros de la comunidad. Así se han generado oportunidades para que científicos de distintas disciplinas, universidades 
y países participen y conozcan a los niños y sus profesores y como resultado se involucren en el programa" (DEVÉS; REYES, 2007, p. 6).

Com esse estímulo, as feiras de ciências têm aumentado consideravelmente nas escolas públicas nos últimos dez anos e muitas delas têm sido promovidas e apoiadas, em grande parte, pelo Programa Explora - Conicyt que oferece:

[...] apoyo en la organización de Ferias Científicas Escolares de establecimientos educacionales y comunas de toda la región. El aporte consiste en distribuir material promocional, realizar difusión del evento y facilitar charlas y jurados, según corresponda. Todo con la finalidad de potenciar las investigaciones en ciencia y tecnología a nivel escolar, fortaleciendo así una cultura científica en la comunidad educativa. (UNIVERSIDAD DE CHILE, 2016)

As aulas mencionadas são qualificadas como o "instrumento más importante de difusión del programa hacia la comunidade (padres, profesores, autoridades comunales, educadores, científicos, políticos)" (DEVÉS; REYES, 2007, p. 5). Tais atividades estão associadas à necessidade de diminuir a complexidade que teria o processo investigativo científico, usualmente restrito ao seu espaço particular, e assim difundir estas investigações para um público geral.

Também são realizados concursos que motivam o desenvolvimento de uma "cultura científica", assim como tentam motivar os estudantes "para estudiar y perfeccionarse para que se transformen en la próxima generación de científicos chilenos"17 (EXPLORA..., 2013). Nesses concursos, concorrem pesquisas realizadas pelos próprios alunos, respondendo a inquietações relacionadas com necessidades das comunidades às quais pertencem suas escolas (CHILE, 2013a). A possibilidade de contribuir na solução de problemas associados à saúde, ao meio ambiente e à proteção dos recursos naturais é vinculada diretamente à aquisição de conhecimento cientifico.

A formação em ciências seria assim instrumento e disciplina capaz de dar solução aos diversos problemas que nos assediam hoje. A compreensão e apropriação, por parte dos alunos, da maneira como os cientistas trabalham permitiria ao aluno assimilar, de forma mais efetiva, aspectos da ciência que seriam necessários para tomar decisões importantes em relação ao cuidado da sua comunidade e da sua saúde e fazê-lo com base na informação científica adequada (HARLEN, 2009). Dessa forma, igualmente, se busca forjar uma disposição favorável à ciência. Entende-se que:

[...] a través de la ciencia bien enseñada, los niños y niñas no sólo podrán avanzar en la comprensión del mundo natural y material, sino que además guiados por sus profesores y profesoras, tendrán oportunidad de experimentar el placer de investigar y descubrir, se apropiarán de las formas de

\footnotetext{
${ }^{17}$ Palavras da Doutora em Astrofísica Maria Teresa Ruiz durante a conferência inaugural do XIV Congresso nacional escolar de ciência e tecnologia (EXPLORA..., 2013).
} 
pensamiento que subyacen a la búsqueda científica y desarrollarán formas de convivencia que estimularán la comunicación efectiva, el trabajo en equipo, el respeto por las ideas del otro y el cuidado de la naturaleza. (DEVÉS; REYES, 2007, p. 2)

No documento de divulgação do V Congresso de Professores de Ciências ${ }^{18}$, é afirmada a relação entre a aquisição de conhecimento científico, a compreensão e intervenção no mundo natural, apontando que, para tal associação, a alfabetização científica é fundamental ao possibilitar os estudantes adquirir: "[...] los conocimientos y habilidades propias de la ciencia que les prepara para entender su entorno con una mirada crítica, reflexiva e informada; cuestiones indispensables para el desempeño exitoso que los estudiantes, futuros ciudadanos, tendrán dentro de la sociedad actual" (CHILE, 2013b, p. 2).

Propósitos vinculados às problemáticas ambientais são destacados quando os mesmos são associados às atitudes científicas, "tales como el respeto por la evidencia e a apertura de mente con a preocupación por los seres vivos y el medio-ambiente" (HARLEN, 2010, p. 10). Estas problemáticas, ainda que não sejam vigentes apenas nos dias de hoje, têm assumido maior espaço nos currículos de ensino fundamental.

No ECBI, faz-se alusão constante ao novo conhecimento em que se fundamenta a aprendizagem das ciências, associado ao "proceso de aprendizaje que emerge de la investigación” (DEVÉS; REYES, 2007, p. 3). Este programa teve como um dos seus objetivos iniciais, ao ser estabelecido o National Science Resource Center (NSRC) pela National Academy of Science, desenvolver uma metodologia relacionada com "procesos similares a los que usan los científicos en la búsqueda de conocimiento" (DEVÉS; REYES, 2007 p. 3) que se "reproduzca en la sala de clases la manera como los científicos generan conocimientos en sus laboratórios" (ALLENDE, 2011, p. 12). Associada ao processo de ensino de Ciências e alicerçada no papel da aprendizagem das ciências e na forma de familiarizá-la com os alunos, a investigação seria a maneira de se apropriar significativamente desse tipo de conhecimento, o que possibilitaria uma atitude positiva frente a esse tipo de aprendizagem. Segundo o programa ECBI:

[...] la solución a los problemas, que enfrentan tanto países en desarrollo como desarrollados, los que han surgido de una disminución en el interés de los jóvenes por estudiar ciencia y tecnología. La consecuencia no sólo se ha remitido a un déficit en la cantidad de científicos e ingenieros, sino en una falta de comprensión del público en general acerca de los aspectos de la ciencia que son precisos para tomar decisiones informadas, como la preocupación por la salud personal y pública, el ambiente y la conservación de la energía. (HARLEN, 2009, p. 1)

\footnotetext{
${ }^{18}$ Este congreso é dirigido "a Profesoras y Profesores de Ciencias de Educación Básica que vinculen su práctica pedagógica con la metodología ECBI o que deseen hacerlo, propiciando un espacio de reflexión e intercambio pedagógico que contribuya al logro de nuevos aprendizajes para la implementación efectiva del modelo en el aula”. (CHILE, 2013b, p. 4)
} 
O objetivo de que os estudantes percorram o trajeto do cientista, para assim se apropriarem de maneira mais responsável do conhecimento, é significado não como um método científico específico nem apenas como a reprodução das atividades realizadas anteriormente para a construção de uma teoria científica. Por “Trajeto do cientista” entende-se o processo de indagação científica na investigação, um modo de ser cientista que transcende às atividades da Ciência. Esse modo de ser tem como fundamento "el nuevo conocimiento sobre el proceso de aprendizaje surgido de la investigación busca llevar al aula las habilidades y actitudes asociadas al quehacer científico" (CHILE, 2015). Simultaneamente, é defendida a democratização da educação científica de qualidade como sendo um direito de todos (CHILE, 2015).

Identificamos, nas políticas de ensino de ciência mais contemporâneas, uma concepção de ensino que coloca a ciência no centro, com o propósito de tomar decisões educativas mais gerais. A ênfase em temas restritos à área científica, incorporados ao currículo, se traduzem em aspectos científicos que os alunos devem adquirir defendendo a necessidade de se apropriar do processo de investigação científica que permitirá “[...] a los estudiantes alcanzar aprendizajes profundos y también, desarrollar un pensamiento crítico, creativo y reflexivo, que podrán usar en todos los ámbitos de la vida." (CHILE, 2013a, p. 11). Embora se faça constantemente a ressalva de que não se pretende fazer uma associação direta entre o mundo científico e escolar ao apontar, por exemplo, que os Objetivos de Aprendizaje explicitados no currículo (CHILE, 2013a) não têm como objetivo principal os alunos "adquirirem todas las destrezas de un científico", senão que possam aproveitar "las oportunidades que les provee el ámbito escolar para desarrollar una determinada manera de pensar, actuar e interpretar el entorno" (CHILE, 2012, p. 6), consideramos que, dentre as diferentes demandas articuladas na constituição destes discursos em defesa do ensino de ciência, permanece uma tentativa por manter a ciência em uma posição de superioridade epistemológica.

Demandas advindas de grupos diversos, assim como critérios de legitimação e interesses vários orientam a constituição de um discurso que tem a pretensão de tornar científica a pedagogia que estrutura o ensino das ciências. No programa estratégico que orienta o ECBI, é apontado que "se pretende promover en todos los niños una mejor comprensión de la naturaleza, estimular su curiosidad y fomentar sus actitudes científicas” (CHILE, 2015). É ainda afirmado que o ECBI é fundamental para alcançar a alfabetização cientifica, entendida como:

[...] la capacidad de los estudiantes para aplicar en su vida diaria los conocimientos y habilidades aprendidas para hacerse preguntas sobre distintos fenómenos y obtener conclusiones basadas en evidencia, les permite comprender el mundo natural, tomar decisiones informadas dentro de él y llevar dichas decisiones a diversas actividades humanas que puedan afectar su familia y su comunidad. (CHILE, 2012, p. 2)

Analogamente ao que já foi discutido em Macedo (2008) para o caso da educação básica no Brasil, a apropriação do conhecimento viria ser uma condição para o exercício da cidadania: o domínio de certos conteúdos (científicos) seria uma condição para a participação cidadã na vida social. 


\section{Conclusões: articulação de demandas em nome da qualidade da educação}

Na constituição desse discurso que denominamos cientificista, múltiplas demandas se articulam. Demandas vinculadas à busca por formas de solucionar problemas sociais por meio do raciocínio e da informação científica, demandas por maior interesse dos alunos em seguir carreiras científicas, por projetar subjetividades científicas, por elevar o status do ensino de ciências aproximando-o do ensino de enfoque acadêmico, por formar um agir cidadão suposto como capaz de resolver questões ambientais, por construir uma pedagogia mais autônoma e científica capaz de levar ao aprendizado de temas científicos. Todas essas demandas articuladas sustentam a construção de um imaginário de luta pela qualidade da educação, por meio da educação em ciências.

Esse discurso, que pode parecer ter origem na educação em ciências, mas assume maior complexidade, mostra-se capilarizado de forma mais ampla no corpo social. É capaz de mobilizar diferentes atores e instituições, formar comunidades epistêmicas em torno da sua defesa. Fornece, simultaneamente, diagnóstico e solução para os problemas educacionais (não apenas do ensino de ciências) que afligem professores, alunos, pesquisadores em educação e a sociedade em geral. Fornece um télos, uma legibilidade (racional e supostamente verdadeira, porque científica) do mundo.

Nesse processo, a representação de uma falta (social) de conhecimentos científicos mobiliza a contraposição a uma pedagogia que não considera suficientemente a ciência na sua formulação teórica. Uma pedagogia, significada como centrada na transmissão de conteúdo, é condenada em nome de uma pedagogia que se supõe mais efetiva, porque baseada na ciência e na indagação. A pedagogia (não-científica), identificada como aquela que formou professores que não sabem ciências, que sustenta uma escola que não valoriza suficientemente as ciências, é expulsa do processo articulatório, em nome da ciência (e dos cientistas), capazes de garantir a qualidade da educação.

Discursos cientificistas, devedores de enfoques empírico-positivistas, na educação em geral e na educação em ciências em particular, não são novos. Tanto estão vinculados às lutas pela hegemonia científica no âmbito da guerra fria (BARROW; CONCANNON; WISSEHR, 2011; KRASILCHIK, 2000) como são vinculados às questões epistemológicas no âmbito da educação em ciências (MATHEWS, 1993). Como espectros, no sentido derridiano (DERRIDA, 1994), são reiterados e suplementados nos discursos atuais. Não são discursos a serem superados como se fosse possível apagar de uma vez por todas suas marcas. Diferentemente e diferencialmente, permanecem nos significando, ainda que sempre sujeitos à indecidibilidade, às múltiplas traduções que faz com que outras leituras sejam feitas, sem origem e sem fim.

Se em outros tempos, as teorias pedagógicas de Jerome Bruner forneceram aportes para sustentar a argumentação em defesa do estudante como cientista-mirim (GAULD, 1988), hoje, no Chile (mas talvez também no mundo), o debate pedagógico parece ser cada vez mais deslocado para a tentativa de construir uma pedagogia baseada na ciência, porque baseada na indagação. Se os discursos cientificistas foram justificados fortemente pela busca do desenvolvimento científico-tecnológico, hoje no Chile esse debate, ainda que não se afaste totalmente da preocupação com o desenvolvimento econômico a ser garantido pela ciência e pela tecnologia, volta-se mais centralmente para a afirmação de que as subjetividades científicas podem propiciar 
a solução de problemas sociais mais amplos, principalmente os problemas ambientais. Não tanto porque se busca levar cada estudante para o laboratório, como soava em propostas vinculadas ao método da redescoberta, mas porque se aposta em levar um cientista para cada escola.

Com isso, a possibilidade de articulação de demandas tão distintas se organiza pelo antagonismo ao que é representado como impedimento à qualidade da educação (científica), como bloqueio à possibilidade identitária de uma "pedagogia científica", representada, no caso do Programa ECBI, como as pedagogias que não valorizam a ciência. Toda identidade bloqueada ao mesmo tempo que impossibilita aquilo que bloqueia, é sua condição de possibilidade. Por significar a escola e os professores como esse lugar da falta de uma "pedagogia científica" indagatória é que se viabiliza a postulação de uma solução científica para a educação.

Deixamos em aberto, para outros trabalhos e outras investigações, a possibilidade de pensarmos com esse processo chileno nos faz compreender também o cientificismo no Brasil atual, não apenas na educação em ciências, mas na própria compreensão e gestão das políticas de currículo.

\section{Referências}

\section{ACADEMIA BRASILEIRA DE CIÊNCIAS. Rede Global de Academias de Ciências}

(IAP). Disponível em: <http://www.abc.org.br/article.php3?id_article=75>. Acesso em: 16 mar. 2016.

ALLENDE, J. El papel de las academias en la educación en ciencias a nivel preuniversitario. In: TALLER LATINOAMERICANO DE ENSEÑANZA DE LAS CIENCIAS EN EL NIVEL SECUNDARIO, 2009, Buenos Aires. [Actas]. Buenos Aires: ANCEFN, 2009.

. La responsabilidad de la comunidad científica y sus instituciones (academias, universidades, sociedades científicas) de trabajar para mejorar el nivel de educación en ciencias. In: TALLER REGIONAL EDUCACIÓN EN CIENCIA, PARA LA CIENCIA Y POR LA CIENCIA, 2011, Montevideo. [Actas]. Montevideo: Unesco, 2011.

ANTONIADES, A. Epistemic communities, epistemes and the construction of (world) politics. Global Society, Abingdon, v. 17, n. 1, p. 21-38, 2003.

BARROW, L.; CONCANNON, J.; WISSEHR, C. Looking back at the Sputnik era and its impact on science education. School Science and Mathematics, Hoboken, v. 111, n. 7, p. 368-375, 2011.

BEECH, J. A internacionalização das políticas educativas na América Latina. Currículo sem Fronteiras, v. 9, n. 2, p. 32-50, 2009. Disponível em: <http://www.curriculosemfronteiras. org/vol9iss2articles/beech.pdf>. Acesso em: 15 fev. 2015.

BUDNIK, J. A. et al. La empresa educativa chilena. Educação \& Sociedade, Campinas, v. 32, n. 115, p. 305-322, 2011. Disponível em: <http://www.scielo.br/pdf/es/v32n115/ v32n115a04.pdf >. Acesso em: 15 fev. 2015. 
CHILE. Decreto $\mathbf{N}^{\mathbf{0}}$ 40. Establece objetivos fundamentales y contenidos mínimos obligatorios para la educación básica y fija normas generales para su aplicación. Santiago: Congreso Nacional de Chile, 24 enero 1996. Disponível em: < http://www.leychile.cl/ $\mathrm{N} ? \mathrm{i}=8043 \& \mathrm{f}=2009-09-25 \& \mathrm{p}=>$. Acesso em: 15 maio 2014.

CHILE. Ley 20370. Establece la ley general de educación. Santiago: Congreso Nacional de Chile, 2009. Disponível em: <http://www.leychile.cl/Navegar?idNorma=1006043\&r=6>. Acesso em: 16 mar. 2016.

CHILE. Agencia de Calidad de la Educación. TIMSS. Disponível em: < http://www. agenciaeducacion.cl/estudios-e-investigaciones/estudios-internacionales/timss-estudiointernacional-de-tendencias-en-matematica-y-ciencias/>. Acesso em: 16 mar. 2016.

CHILE. Ministerio de Educación. Bases curriculares: ciencias naturales. Santiago, 2012. Disponível em: < http://www.curriculumenlineamineduc.cl/605/articles-21313_programa. pdf $>$. Acesso em: 15 jan. 2014.

. Bases curriculares $7^{\circ}$ y $8^{\circ}$ básico; $1^{\circ}$ y $2^{\circ}$ medio: ciencias naturales. Santiago, 2013a. Disponível em: <http://www.auladigital.cl/sminforma/documentos/bases/ bases_7_a_2_medio_ciencias_naturales.pdf>. Acesso em: 14 jan. 2014.

. V Congreso nacional y Latinoamericano de ciencias en educación básica.

[S.l.: s.n.], 2013b. Disponível em: < http://www.textosescolares.cl/usuarios/basica/ doc/201308161319090.VCongreso-Convocatoria.pdf>. Acesso em: 07 out. 2014.

DERRIDA, J. Espectros de Marx. Rio de Janeiro: Relume-Dumará, 1994.

DEVÉS, R.; REYES, P. Principios y estrategias del Programa de Educación en Ciencias basada en la Indagación (ECBI). Pensamiento Educativo: revista de investigación educacional latinoamerica, Santiago, v. 41, n. 2, p. 115-131, 2007. Disponível em: < http:// pensamientoeducativo.uc.cl/index.php/pel/article/view/419>. Acesso em: 28 mar. 2016.

DIAS, R. E. Demandas das políticas curriculares para a formação de professores no espaço ibero-americano. e-Curriculum, São Paulo, v. 11, n. 2, p. 461-478, 2013. Disponível em: $<$ http://revistas.pucsp.br/index.php/curriculum/article/view/16617>. Acesso em: 15 fev. 2015.

DONOSO DÍAZ, S. D. La reproducción de la desigualdad intergeneracional y nuevas formas de exclusión social producto del diseño político del sistema educacional chileno. Caderno CRH, Salvador, v. .24, n. 61, p. 135-152, 2011. Disponível em: < http://www. redalyc.org/articulo.oa?id=347632183010>. Acesso em: 22 mar. 2016.

ECBI CHILE. Enfoque sistémico. [S.l.: s.n.], [2015]. Disponível em: <http:/ /www. ecbichile.cl/home/enfoque-sistemico/>. Acesso em: 22 mar. 2016.

EVOLUCIÓN del programa ECBI 2002-2012. [S.1.: s.n.], [2012]. Disponível em: <http:// www.ecbichile.cl/wp-content/uploads/2012/05/Historia-del-programa-ECBI-2003-2012. pdf $>$. Acesso em: 22 mar. 2016. 
EXPLORA: Programa Nacional de Divulgación y Valoración de la Ciencia y la Tecnología. [S.l.: s. n.], 2013. Disponível em: <http://www.conicyt.cl/explora/2013/11/26/comienza-elxiv-congreso-nacional-escolar-de-ciencia-y-tecnologia/>. Acesso em: 22 mar. 2016.

FUNDACIÓN Andes recibe Premio Patrimonio Cultural de Chile. E1 Mercurio en internet, Santiago, 28 oct. 2004. Disponível em: < http:/ /www.emol.com/noticias/ magazine/2004/10/28/162260/fundacion-andes-recibe-premio-patrimonio-cultural-dechile.html>. Acesso em: 20 nov. 2014.

GAULD, C. The "pupil-as-scientist" metaphor in science education. Research in Science Education, Dordrecht, v. 18, n. 1, p. 35-41, 1988.

HARLEN, W. Aprendizaje y enseñanza de ciencias basados en la indagación. [S.l.: s.n.], 2009. Disponível em: <http://pt.scribd.com/doc/149587762/Aprendizaje-yensen-anza-de-ciencias-basados-en-la-indagacio-n\#scribd >. Acesso em: 23 mar. 2016.

. Evaluación y educación en ciencias basada en la indagación: aspectos de la Política y la Práctica. Trieste: Global Network of Science Academies, Science Education Programme, 2013. Disponível em: < http://interacademies.net/Publications/25001.aspx>. Acesso em: 23 mar. 2016.

. (Ed.). Principios y grandes ideas de la educación en ciencias. [S.l.: s.n.], 2010. Disponível em: < http://www.gpdmatematica.org.ar/publicaciones/Grandes_Ideas_de_la_ Ciencia_Espanol.pdf $>$. Acesso em: 23 mar. 2016.

INFANTE JARAS, M.; MATUS CÁNOVAS, C.; VIZCARRA REBOLLEDO, R. Razonando sobre la idea de diferencia en las politicas educativas chilenas. Universium, Talca, v. 26, n. 2, p. 143-163, 2011. Disponível em: < http://dx.doi.org/10.4067/S071823762011000200008>. Acesso em: 22 mar. 2016.

KRASILCHIK, M. Reformas e realidade: o caso do ensino das ciências. São Paulo em Perspectiva, São Paulo, v. 14, n. 1, p. 85-93, 2000. Disponível em: <http://dx.doi. org/10.1590/S0102-88392000000100010>. Acesso em: 17 mar. 2016.

LACLAU, E. Nuevas reflexiones sobre la revolución de nuestro tiempo. Buenos Aires: Nueva Visión, 2000.

A razão populista. São Paulo: Três Estrelas, 2013.

LOPES, A. C. Ainda é possível um currículo político? In: LOPES, A. C.; ALBA, A. (Org.). Diálogos curriculares entre Brasil e México. Rio de Janeiro: EdUERJ, 2014. p. 43-62.

. A qualidade da escola pública: uma questão de currículo? In: TABORDA, M. et al. (Org.). A qualidade da escola pública. Belo Horizonte: Mazza, 2012. p. 15-29.

LOPES, A. C.; CUNHA, E.; COSTA, H. H. C. Da recontextualização à tradução: investigando políticas de currículo. Currículo sem Fronteiras, v. 13, p. 392-410, 2013. Disponível em: < http://www.curriculosemfronteiras.org/vol13iss3articles/lopes-cunhacosta.pdf $>$. Acesso em: 22 mar. 2016. 
LOPES, A. C.; MACEDO, E. Teorias de currículo. São Paulo: Cortez, 2011.

MACEDO, E. Currículo como espaço-tempo de fronteira cultural. Revista Brasileira de Educação, Rio de Janeiro, v. 11, n. 32, p. 285-372, 2006. Disponível em: <http://www. scielo.br/pdf/rbedu/v11n32/a07v11n32.pdf>. Acesso em: 22 mar. 2016.

. Que queremos dizer com educação para a cidadania? In: LOPES, A. C. et al. (Org.).

Políticas educativas e dinâmicas curriculares no Brasil e em Portugal. Petrópolis: DP\&A, 2008.

MATHEUS, D. S.; LOPES, A. C. Sentidos de qualidade na política de currículo (2003-2012). Educação e Realidade, Porto Alegre, v. 39, n. 2, p. 337-357, 2014. Disponível em: <http:// seer.ufrgs.br/index.php/educacaoerealidade/article/view/41018/28857>. Acesso em: 22 mar. 2016.

MATHEWS, M. Constructivism and science education: some epistemological problems. Journal of Science Education and Technology, Dordrecht, v. 2, n. 1, p. 359-370, 1993.

OLIVEIRA, G. G.; OLIVEIRA, A. L.; MESQUITA, R. G. M. A teoria do discurso de Laclau e Mouffe e a pesquisa em educação. Educação e Realidade, Porto Alegre, v. 38, n. 4, p. 1327-1349, 2013. Disponível em: <http://www.seer.ufrgs.br/index.php/ educacaoerealidade/article/view/29574/27763>. Acesso em: 12 dez. 2014.

SCHWARTZMAN, S. Chile: um laboratório de reformas educacionais. In: SEMINÁRIO SOBRE A QUALIDADE DA EDUCAÇÃO BÁSICA, 2007, Brasília. [Anais...]. Disponível em: <http://www.schwartzman.org.br/simon/paperChile.pdf>. Acesso em: 20 nov. 2014.

TORRES, W. N.; DIAS, R. E. Comunidades epistêmicas nas políticas de currículo em EJA. In: LOPES, A. C.; DIAS, R.; ABREU, R. G. (Org.). Discursos nas políticas de currículo. Rio de Janeiro: Quartet: Faperj, 2011. p. 205-224.

UNIVERSIDAD DE CHILE. Jorge Allende Rivera. Disponível em: < http://www.uchile. $\mathrm{cl} /$ portal/presentacion/historia/grandes-figuras/premios-nacionales/ciencias-/6610/jorgeallende-rivera $>$. Acesso em: 22 mar. 2016.

ZIBAS, D. A. A reforma do ensino médio no Chile: vitrina para América Latina? Cadernos de Pesquisa, São Paulo, n. 115, p. 233-262, mar. 2002. Disponível em: < http://dx.doi. org/10.1590/S0100-15742002000100010>. Acesso em: 23 mar. 2016.

Artigo recebido em 04/04/2015. Aceito em 21/10/2015.

Endereço para contato: Universidade do Estado do Rio de Janeiro (UERJ), Programa de Pós-Graduação em Educação, Rua São Francisco Xavier, 524, Grupo 12.037-F, CEP 20550-013, Rio de Janeiro, RJ, Brasil. 